\title{
IMPAIRED IDENTIFICATION OF FACES AND PLACES WITH AGNOSIA FOR COLOURS

\author{
REPORT OF A CASE DUE TO CEREBRAL EMBOLISM
}

\author{
BY \\ C. A. PALLIS \\ From the Department of Neurology, Cardiff Royal Infirmary
}

\begin{abstract}
Wheresoe'er I turn my view
All is strange, yet nothing new ...

SAMUEL JOHNSON
\end{abstract}

Visual agnosia usually develops in a context of diffuse or progressive cerebral disease. The disorder is often difficult to analyse because of associated dysphasic disturbances, visual field defects, drowsiness or impaired attention, poor memory, inadequate insight, or " mental confusion". In other instances the difficulties are due to a low initial intelligence, to undue suggestibility, or to an abnormal emotional reaction. Symptoms of agnosia in patients with raised intracranial pressure or diffuse cerebral arteriosclerosis are notoriously difficult to evaluate.

It must be very rare indeed for agnosia to develop acutely and to constitute the sole disability in a person of high intelligence and good personality. I have recently had the opportunity of observing one such patient in whom cerebral embolism was the basis of a "visual agnosia", strikingly selective in its manifestations. The case is described here in some detail as it probably has important neurological implications concerning the status of prosopagnosia (agnosia for faces) and its relation to achromatopsia (colour agnosia), and to a peculiar, and I believe hitherto unrecorded, disorder of spatial thought.

Critchley (1953) in a recent discussion on " parietal" symptomatology has emphasized the inadequacy of many case reports and the difficulties involved in deciding whether the failure to mention certain complex phenomena should imply that they were in fact absent, or merely that they were not specifically sought for. In a case such as the one about to be described fairly detailed comment as to the absence of certain signs and symptoms is therefore not only permissible but proper.

In the following case report the patient's own words are quoted wherever possible. He wrote a full account of his experience from which certain passages are here excerpted.

\section{Case Report}

A. H., aged 51, a mining engineer and colliery manager, was admitted to the Neurological Department, Cardiff Royal Infirmary, on January 4, 1954. He had suffered from chorea in childhood. In 1948 mitral stenosis was diagnosed. In 1952 he developed auricular fibrillation and slight congestive failure and spent five weeks in hospital. He responded well to treatment and returned to work. There had been no embolic episodes that he was aware of.

On the evening of June 10, 1953, he suddenly felt unwell after a couple of drinks at his club. He called out for help but remembered nothing of the events of the subsequent 12 hours. He did not lose consciousness. He appeared confused, was taken home by car, and had to be helped to bed. He spent a restless night, complaining of headache, but did not vomit.

"At about 8 o'clock next morning I got out of my bed. My mind was clear but I could not recognize the bedroom. I went to the toilet. I had difficulty in finding my way and recognizing the place. Turning round to go back to bed I found I couldn't recognize the room, which was a strange place to me ..."

"I could not see colour, only being able to distinguish light objects from dark ones. Then I found out all faces were alike. I couldn't tell the difference between my wife and my daughters. Later I had to wait for my wife or mother to speak before recognizing them. My mother is 80 years old."

On the first morning he had complained of heaviness of the left hand and of a "stinging" feeling in the left index finger and about the angle of the mouth, on the left side. Both these symptoms cleared within a few days. At no time was there any difficulty in the utterance or comprehension of speech. His subsequent behaviour was normal, although he became more reticent than usual. He showed no evidence of apraxia and could shave, dress himself, do up his shoe laces, and make his bed. Within a few days his only residual symptoms pertained to vision and to the interpretation of things seen.

He became almost immediately aware of an altitudinal scotoma in each eye. "Below, I can see detail quite clearly. Then there is a narrow blotch of darkness across the middle of whatever I look at. It has a straight 
lower edge but on top and at the sides the border is less sharp. Whether I shut one eye or the other, things look much the same. I have learned to look above the blotch to pick out any details originally missed."

Colour perception was totally lost. "Everything appears in various shades of grey. My shirts all look dirty and I can't tell one of them from the other. I have no idea which tie to wear." "I can't tell whether the light in a room is on or off and from a distance I don't know whether the fire is burning or not." "I have difficulty in recognizing certain kinds of food on my plate, until I have tasted or smelled them. I can tell peas or bananas by their size and shape. An omelette, however, looks like a piece of meat and when I open a jar I never know if I'll find jam or pickles in it !" $\mathrm{He}$ readily recognized individual items of cutlery, glassware, furniture, garden tools, or other objects in everyday use, " provided colour isn't the main clue as to what it is",

The patient analysed his difficulty in identifying faces with considerable insight. "I can see the eyes, nose, and mouth quite clearly but they just don't add up. They all seem chalked in, like on a blackboard. I have to tell by the clothes or voice whether it is a man or woman, as the faces are all neutral, a dirty grey colour. The hair may help a lot, or if there is a moustache." "All the men appear unshaved." "I cannot recognize people in photographs, not even myself. At the club I saw someone strange staring at me and asked the steward who it was. You'll laugh at me. I'd been looking at myself in a mirror." " I later went to London and visited several cinemas and theatres. I couldn't make head or tail of the plots. I never knew who was who." "I bought some copies of Men Only and London Opinion. I couldn't enjoy the usual pictures. I could work out what was what by accessory details, but it's no fun that way. You've got to take it in at a glance."

He had some difficulty with animal faces also. "They are easier to recognize than human faces, because the rest of an animal varies so much more than does the rest of a man. In real life I could tell a cat from a dog, or a horse from a cow, but it would be more difficult from pictures, especially if only the. face is shown."

He had no difficulty in revisualization. "I can shut my eyes and can well remember what my wife looked like or the kids." He described his dreams à " not frequent, but just as vivid as before". He therefore showed none of the features of what Nielsen (1946) called "irreminiscence", the syndrome described by Charcot (1883) and Wilbrand (1887) and characterized by a failure to conjure up visual images and by a loss of the visual components of dreaming.

He complained a lot of his inability to recognize places. There was no loss of topographical memory. "In my mind's eye I know exactly where places are, what they look like. I can visualize T . . . Square without difficulty, and the streets that come into it." "I know the order of the shops." "I can draw you a plan of the roads from Cardiff to the Rhondda Valley." "It's when I'm out that the trouble starts. My reason tells me I must be in a certain place and yet I don't recognize it. It all has to be worked out each time. For instance, one night, having taken the wrong turning, I was going to call for my drink at the Post Office. I got back to the main street and took my usual turn again." Or even more strikingly: "My difficulty with buses is to know where to get off. Two colleagues of mine once got on at the same stop. One of them was a totally blind man. I told them I wanted to get off at P . . . Square. The blind man offered to put me down there, which he did without trouble."

He seemed to have difficulty in assimilating new topographical data. "It's not only the places I knew before all this happened that I can't remember. Take me to a new place now and tomorrow I couldn't get there myself."

He stated that during the first weeks of his illness there had been some difficulty in reading, but that this had rapidly cleared up. He was an observant witness and there were no residual dyslexic difficulties. He did not think his calculating ability had been affected. There had been no "body-image" disorders.

$\mathrm{He}$ was questioned closely as to whether he thought his sense data for visual synthesis were adequate. His engineering training made it easy for him to grasp the issue at stake : he did not consider his " raw materials" defective. He was emphatic that the scotomata, "although a nuisance were not what really mattered", and he made the very pertinent enquiry as to why, if they were of significance, they should prevent him from identifying faces but did not interfere with his perception of other objects. He admitted that the loss of colour vision contributed to his difficulties. He was occasionally "worried by the nearness of things" and gave an excellent description of the phenomenon of pelopsia : "the eyes have become telescopic. Things sometimes seem just on top of me, although not particularly large. Well known distances appear a third of what they ought to be." There was no other impairment of stereoscopic vision and the landscape had normal relief. He could assess without difficulty the relative propinquity of various objects, both in front of him and on either side. The dimensions of objects looked at were in no way distorted, there was no abnormal tilt to their edges and no blurring, discontinuity, or movement of their outline. There was no complaint of visual perseveration and no abnormal affective reaction to the objects in his monochromatic world. They appeared to him neither sinister nor endowed with particular charm, but-not unnaturally" rather dull".

Examination.-On examination on January 4, 1954, mitral stenosis and auricular fibrillation were found. The ventricular rate was 70 to 80 per minute. There was a minimal pulse deficit. Blood pressure was $130 / 90 \mathrm{~mm}$. Hg. He was receiving "digoxin". There was no evidence of congestion and no signs of bacterial endocarditis.

He was right-handed. On neurological examination the only abnormalities detected were in the visual fields (Fig. 1). Uncorrected acuity was $6 / 6$ in each eye. The fundi were normal. On the perimeter there were narrow non-congruous homonymous sector defects in the left 


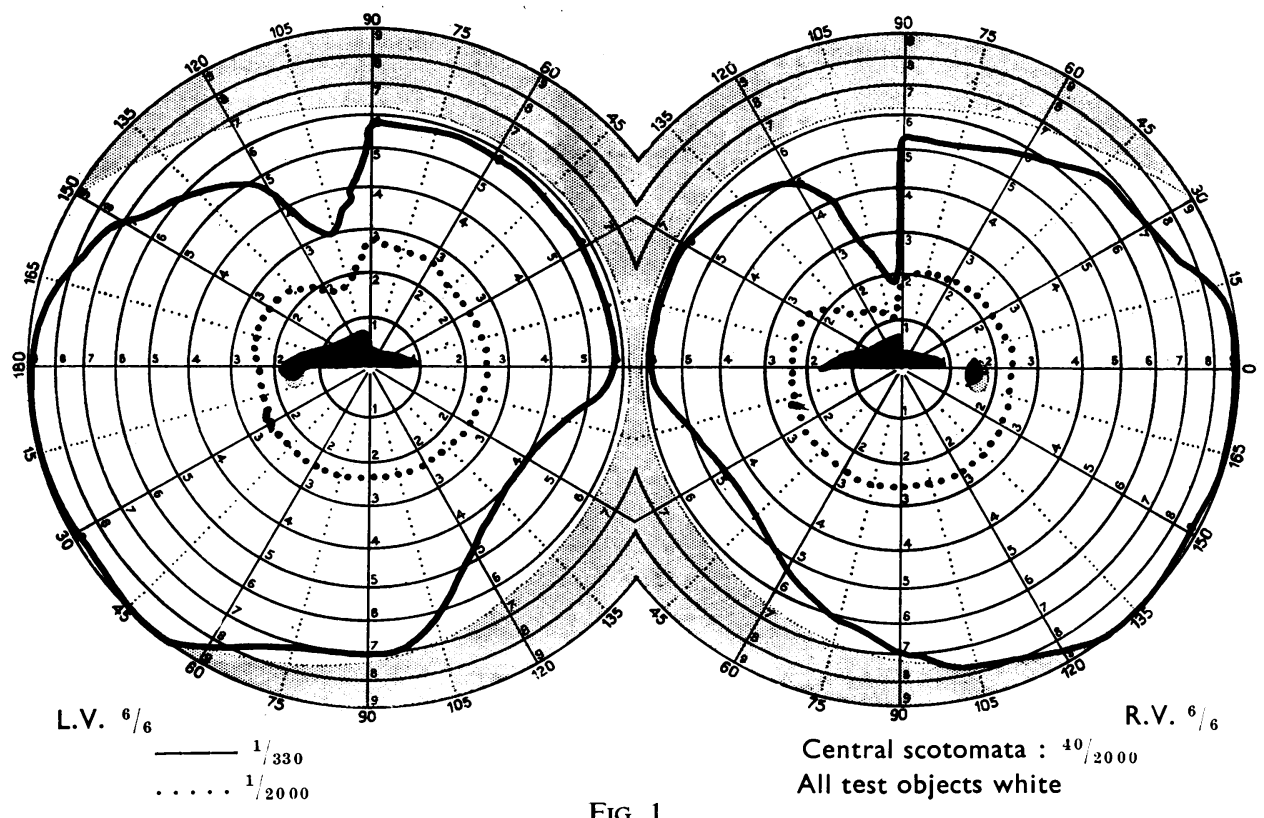

FIG. 1

upper quadrants, well shown by the 1/330 isopters. (The patient was unaware of these defects.) A central defect in each field was further explored on the screen. The patient was an excellent witness and gave consistent replies on repeated testing. A $40-\mathrm{mm}$. white object outlined a large "altitudinal" absolute scotoma in each field extending both sides of the vertical meridian. Each scotoma was limited inferiorly by the horizontal meridian, except where fusion with the blind spot had occurred. (In Fig. 1 these central defects are recorded on the same scale of coordinates as used for the $1 / 330$ isopters. These "half-moon" shaped central defects are best considered as made up of two adjacent quadrantic scotomata, each with its apex at the fixation point.) A $50 \%$ reduction in illumination did not markedly alter the size of the defects. Confrontation tests revealed no visual inattention. He localized objects accurately in both right and left half-fields.

Stereognostic perception was excellent, even when wearing a pair of surgical rubber gloves. He localized stimuli accurately in the limbs and discriminated normally between single, double, and treble stimuli applied to various parts of the body. Graphaesthetic sense was not impaired. Detailed and repeated sensory testing failed to reveal-or to induce-any "cortical" type of sensory loss.

He was of above average intelligence and his general level of awareness was extremely keen. His memory was remarkable. He repeated the Babcock sentence correctly at the first attempt and his span of digit retention was eight forwards and six backwards. There was no hesitation in his speech and he could obey complex orders. He read smoothly and had no trouble in understanding and later describing what he had read. "Spontaneous " writing, and writing to dictation were orderly and he made no spelling mistakes. He promptly recog- nized, named, and demonstrated the use of a wide variety of test objects. He showed no difficulty in sorting out geometrical figures according to form and complicated patterns were promptly recognized. The significance of line drawings was immediately apparent to him and he could accurately describe the content of various pictures he was shown. He had no difficulty in identifying his own fingers or those of his examiner or any other part of their respective anatomies, including mouth, nose, eyes, and ears. There was no right-left confusion or acalculia. He could draw well : his daisies were most artistic and his bicycles showed a wealth of accurate technical detail. There was no neglect or imperception of any part of extrapersonal space. He could assemble a jig-saw puzzle and he showed no constructional apraxia in "match-mosaic" tests. He could play draughts and chess-but found playing cards too much effort.

He mixed readily with the other patients in the ward but rarely spoke unless spoken to first. He could not identify his medical attendants. "You must be a doctor because of the coat, but I don't know which one you are. I'll know if you speak." He failed to identify his wife during visiting hours. She was told one day, without his possible knowledge, to walk right past his bed but he did not show the least sign of recognition. Repeated attempts were made to "catch him out" but none succeeded. If the disability was a feigned one, it was a performance of quite unbelievable virtuosity and consistency. He made repeated journeys to various parts of the hospital and got lost on several occasions. $\mathrm{He}$ once walked into a female ward by mistake. Neither its disposition nor its occupants struck him as any different from those of the ward he had just left.

The "prosopagnosia" was specifically investigated. $\mathrm{He}$ failed to identify pictures of $\mathrm{Mr}$. Churchill, $\mathrm{Mr}$. 
Aneurin Bevan, Hitler, Stalin, Miss Marilyn Monroe, or Mr. Groucho Marx. When confronted with such portraits he would proceed deductively, analysing one feature after another, searching hard for the " critical detail " which would yield the answer. In human faces, this was rarely forthcoming. There was somewhat less difficulty with animal faces. A goat was eventually recognized by its ears and beard, a giraffe by its neck, a crocodile by its dentition, and a cat by its whiskers.* With none of these animals could he immediately grasp the meaning of the face. He took five to 10 seconds over each picture. The face of a monkey lacked " critical detail" and was not identified.

Investigations.-Radiographs of the skull showed no abnormality. The Wassermann and Kahn tests were negative in the blood. The cerebrospinal fluid was normal in pressure and composition. The electroencephalogram was normal. Vertebral angiography (Dr. Arthur M. Jones) showed defective filling of the right posterior cerebral artery, the right vertebral artery having been punctured. The other branches of the basilar artery and the left posterior cerebral artery (and its terminal branches) were well outlined.

\section{Discussion}

The main features of this most unusual case may be summarized as (1) achromatopsia (colour agnosia); (2) a disorder preventing the identification of faces ; (3) a peculiar disorder of spatial thought which rendered the patient incapable of identifying places (but without impairment of topographical memory, spatial imperception or neglect, or difficulty in recognizing landmarks); (4) an almost complete absence of other " parietal " signs or symptoms; (5) scotometric evidence of small bilateral occipital lesions.

The Achromatopsia.-Achromatopsia denotes an inability to perceive colour distributed throughout the whole of both visual fields. Any abnormality confined to part of the field is more akin to disorder of the visual analysers than to the " higher level " disturbances considered here. Achromatopsia of cerebral origin may occur without visual field defect although Critchley (1953) considers it "doubtful whether colour sense can be altered . . . without some corresponding disturbance in the appreciation of form ". Whether achromatopsia ever develops in the absence of other defects of gnosis is still the subject of controversy. Nielsen (1941) maintains that small cerebral lesions may affect selectively the recognition of certain attributes of objects in general (such as colour, form, dimension, and movement) and, to some extent, the case here reported supports this contention.

It is not yet known whether achromatopsia has

*In these respects he showed a striking resemblance to Bodamer's Case 2 (vide infra) who eventually recognized a portrait of Hitler by the Bard und Scheitel (moustache and parting). any localizing or even lateralizing significance. Critchley (1953) believes that it may occur with unilateral cerebral disease, and that the lesion is then usually in the dominant hemisphere. The patient A. H. had bilateral infarcts but the size and shape of the field defects show that the main lesion was right-sided. The only unequivocal evidence of disease in the left hemisphere was provided by those small parts of the scotomata in each field situated to the right of the vertical meridian. The left-sided lesion was situated very far back, in the infracalcarine striate cortex. If this small lesion is of no significance in causing achromatopsia it must be conceded (1) either that the symptom may arise from disease affecting the subordinate right hemisphere (of which there was evidence in the shape of the initial left-sided paresis and facio-brachial paraesthesiae and of the sector defects in the left upper quadrants) or, (2) that achromatopsia may be virtually the only reflexion of a dominant hemisphere lesion, or, finally (3) that bilateral disease is necessary for achromatopsia to develop and that the left-sided lesion may be clinically silent.

It is difficult to know what role to attribute to small occipital infarcts revealed by scotometry. Spalding (1952) has carefully studied the effects of penetrating injuries to the striate cortex and many of the recorded visual fields in his excellent study showed small quadrantic scotomata, with their apices at the fixation-point, very similar to those of patient A. H. Total achromatopsia was not encountered with these partial lesions (personal communication).

This case illustrates how achromatopsia may arise on the basis of localized brain disease, causing few other symptoms or signs. It does not help, however, in the vexed question of whether such disease needs to be bilateral, or, if the symptoms can arise from unilateral disease, which hemisphere is the most likely to be responsible.

The Prosopagnosia.-It is not well established whether considerations of cerebral dominance are of the same importance in the recognition of general visual data as they are in the recognition of symbols (such as letters and numbers). Lesions of the dominant parietal cortex (Brodmann area 39) or of its afferent fibres from the striate cortex affect the recognition of written symbols and the results of such lesions are but poorly "compensated". With lesions of the shorter pathways between the striate cortex (area 17) and adjacent occipital area 18 (or with lesions of area 18 itself) it is the recognition of other (non-symbolic) visual data that is affected, and here experience shows that considerable improvement follows unilateral lesions in the dominant 
occipital lobe. Current opinion, therefore, has it that bilateral lesions are necessary for permanent symptoms of visual agnosia to develop.

Critchley (1953) states that "visual agnosia . . . must be admitted as a rarity in clinical practice". He enumerates a number of points which may throw doubt on whether a patient's disability is in fact a visual agnosia : quantitative and qualitative visual defects, the absence of visual imagery, the presence of dysphasia or other gnosic or praxic difficulties, general mental confusion, and the absence of insight into the disability (anosognosia). Many of the classical recorded cases of visual agnosia showed these associated features in varying degree, and their interpretation is hence very difficult. There were few such complicating factors in the patient here described.

The "agnosia" in this patient was highly differentiated in its manifestations. Opinion is divided on whether such specific forms of visual agnosia do in fact occur. Nielsen (1941) distinguished between agnosia for animate and agnosia for inanimate objects which he relates to lesions of the upper and lower parts of Brodmann's area 18 respectively. Teitelbaum (1943) analysed agnosia into numerous variants. To Critchley (1953), however, "pure cases of partial and specific visual agnosia suggest both an incompleteness of the clinical study and an ignorance of the intricate modifications of the patient's total kehaviour".

In most case reports of prosopagnosia the symptom is only a facet of a more widespread disturbance (Müller, 1892; Goldstein and Gelb, 1918 ; Heidenhain, 1927). Hoff and Pötzl (1937) recorded its occurrence in almost isolated form, but in a patient also suffering from loss of visual memory. More recently Bodamer (1947) propounded an elaborate psychological theory to account for his observations in two patients in whom prosopagnosia was the outstanding feature. Both had sustained, among others, bilateral occipital injuries. Neither of these cases had experienced difficulty in revisualizing long-familiar faces. (Bodamer's third patient differed in several respects and was probably suffering from a metamorphopsia confined to faces, without prosopagnosia.) It is of considerable interest that colour vision was affected in both Bodamer's cases and in all the cases mentioned above. Cases of prosopagnosia have, however, been described in which colour vision was not affected (Jossmann, 1929).

According to Bodamer (1947) the human face is in a perceptual category of its own. Other forms of agnosia are not necessarily associated with prosopagnosia (the dissolution of the special function of identifying faces). In prosopagnosia, the patient, although still able to recognize the separate components of a face, is no longer capable of the synthesis permitting identification of the physiognomy as a whole. The defect was considered a manifestation, confined to the face, of what Wolpert (1930) had termed "Simultanagnosie". There was a defect in the " simultaneous " awareness of the perceptual data underlying physiognomy. Bodamer rejects the idea that this was due to the field defects shown by both his patients.

Bodamer went further, however. An eye-area, or "ocula", as he called it, had been "spared" in both his patients. Reference to the work of certain child psychologists suggested that, ontogenetically, this eye-area was of considerable importance. Bodamer considered his patients with prosopagnosia to have reverted to an infantile phase of perception. Apart from the eye area they perceived but little of the faces of those about them, which appeared blurred.

Whatever one's views about Bodamer's theories, his detailed case reports, together with a few others, offer some clinical evidence for the concept of an unusual, and perhaps specific, disorder in the "visuognosic" sphere concerning the identification of faces. The precise scotometric data in the present case may be of relevance. The total data suggest that the disturbance may arise as a result of bilateral occipital lesions, but there are too few case reports with detailed visual field studies or necropsy confirmation for one to have any certainty about the localizing value of the symptom.

Comment seems called for as to the propriety of the term " prosopagnosia" to denote an inability to identify faces. Patients with this disability are rarely in any doubt as to the fact that it is faces that are situated above the necks of those about them. Modern art may depict a variety of objects at this site but it is doubtful if such apparitions are ever part of the experiential world of patients with parieto-occipital disease. Individual facial features, however distorted they may appear from metamorphopsia, are usually perceived for what they are (an eye, a nose, a mouth) and their geometric relationship is usually preserved. There is clearly more to a face than the sum of its structural components. Colour is probably not of fundamental importance. A portrait in black and white is recognized as easily as a portrait in colour.

It is suggested that the fundamental defect, in this case and perhaps in others, was not in the visual sphere. Neither was it agnosia in the ordinary sense. Faces were recognized as faces, they were not icentified as particular faces. There was there- 
fore difficulty in appreciating the full significance of what had been seen and recognized and there followed an inability to fit such data into the pattern of previous experience. Faces failed to elicit the engrams forming the basis of memory although memory itself was not impaired and there was no difficulty in "re-visualization". The disturbance was probably at a higher level than gnosis.

The Disorder of Spatial Thought.-The patient's inability to recognize places was a most unusual disturbance of spatial thought. His topographical memory was good, as could be inferred from his accurate descriptions of paths, roads, the layout of the mine-shafts, and from his excellent performance in drawing maps of places familiar to him before his illness. There was no evidence of neglect or imperception of any part of extrapersonal space, localization of objects in space was excellent, and he showed no difficulty in interdimensional spatial manipulations. There was no loss of stereoscopic vision (Riddoch, 1917 ; Holmes and Horrax, 1919) and no visual allo-aesthesia (Herrmann and Pötzl, 1928).

Orientation in abstract space, known to him before his illness, was normal. For instance, he could outline, on plan of Cardiff, the appropriate route for getting from the hospital to the railway station or football stadium. Yet when confronted with the concrete task of so doing his performance was poor. He would have difficulty in reconciling the reality about him with the plan in his mind in convincing himself that he was in a given situation. "I have to keep the idea of the route in my head the whole time, and count the turnings, as if I were following instructions that had been memorized." "The places are all strange, yet common sense tells me they are not new to me."

At a purely conceptual level there did not appear to be anything unusual in his ideas about space. Critchley (1953) has stressed the variability of such ideas in normal people. "The conceptions of space held by a philosopher, a mathematician, and an artist are probably very different one from the other-and all of them are quite unlike the naïve ideas of the ordinary layman." A. H.'s ideas of space were doubtless those of a graduate of the University of Wales with a B.Sc. degree in engineering and with little, if any, inclination for metaphysical speculation. He was a perfectly normal person in all these respects.

It is suggested that his difficulties in spatial orientation were of a type not hitherto well recognized and derived from an inability to assimilate environmental experience completely. His environ- ment lacked perhaps some subtle attribute which one might call topographical significance. I do not wish to imply that he was unaware of the nature of houses or streets. He could at a glance tell terraced council-houses from detached villas, a living room from an office, a country lane from a main road. There was therefore no agnosia for landmarks. Such objects, however, normally elicit more than a formal recognition. They are not merely " houses" or " roads", they are particular houses, housesin-a-certain-position, particular roads, roads-goingfrom-A-to-B ; they have, in fact, a specific and topographical as well as an abstract and generic significance.

It is suggested that, devoid of this attribute of topographical significance, the patient's surroundings failed to elicit the appropriate topographical memories. Identification of a particular environment was therefore defective although there was no misinterpretation of the nature of its individual components. The similarity between this presumed disorder and his difficulty in identifying faces is apparent. In neither instance was the disturbance primarily one of the visual analysers nor was it agnosia as usually understood. Identification failed, in the presence of perceptual data adequate for gnosis, in the ordinary sense. (It is probably no coincidence that a defect of identification, as distinct from recognition, should, in everyday life, manifest itself in precisely such perceptual categories as faces and places.)

A defect such as the one envisaged would account for (1) his persistent difficulty in identifying previously well known places or faces, and (2) his inability to remember new places or faces. We have all experienced the peculiar sensation felt on visiting a strange town for the first time. Although at first devoid of topographical significance for the observer, the new buildings and streets, the " feel of the place" rapidly acquire meaning. At a subsequent visit the impression is a very different one. When meeting people for the first time something similar occurs. They cease to be people and become persons. The patient was perhaps incapable of this adjustment. New surroundings or faces, seen for the first time after his illness, retained indefinitely their quality of newness. Perhaps they could not be incorporated as memory because, to the patient, they were lacking in some essential attribute. Previously known places and faces, again lacking this attribute, failed to elicit remembrance. Memory is, after all, an aggregate of sensory experiences, each occurring within certain patterns of circumstance, each engendering certain affective reactions (often beyond the realm of consciousness), and each definitely 
related to certain coordinates of time and space. Devoid of this garb, who knows how easily new experience could be registered, or previous experience recalled?

Other Possible Interpretations.-This case offers no real support for the Gestalt theory of visual agnosia propounded by Goldstein and Gelb (1918). With regard to such special object-categories as places and faces there was, it is true, a discrepancy between the recognition of parts and the identification of the whole, but the tests resorted to revealed no abnormality in the formation of primitive visual Gestalten. There were no persistent dyslexic difficulties, and all geometrical figures were readily recognized without recourse to the tracing movements of head or hand exhibited by Goldstein and Gelb's famous patient Schn. It is, moreover, difficult to conceive of a disorder of Gestalt formation so highly specific in its manifestation.

Could the patient's disability be explained on the basis of other defects of what Lissauer (1889) called "apperception"? Much modern work stresses the importance of subtle functional disturbances in the visual analysers in causing symptoms usually attributed to agnosia. Bay (1953), for instance, doubts there is any such clinical entity as visual agnosia and holds that what is usually so denoted is in fact a primary sensory defect complicated by a variable degree of dementia. As he graphically puts it, "sensory defect and mental deterioration increase and multiply each other". The new techniques for testing perception in various parts of the visual field (tachistoscopy, local adaptationtime, rate of flicker-fusion) will often show the " effective field" to be of smaller dimensions than the field determined by perimetry or scotometry under standard (optimum) conditions. In Bay's view prosopagnosia results in most cases from contraction of the effective field to less than $5^{\circ}$. Such a field precludes a simultaneous survey of the face, and hence will prevent the patient from obtaining a "Gestalt of the physiognomy". A similar interpretation is offered by Bay for the disorders of spatial orientation not infrequently accompanying prosopagnosia and relating to environments first encountered after the onset of the disorder.

In relation to these claims it may be pointed out that the patient here described had a visual acuity of $6 / 6$ in each eye (despite his scotomata), that metamorphopsia was minimal (occasional pelopsia only), and that there was no hint of dementia. Special tests to assess local adaptation-time and the rate of flicker-fusion have not been performed to date, neither has tachistoscopy. It seems, however, improbable that any abnormalities revealed by these techniques would have resulted in an effective field of less than $5^{\circ}$, in view of the position of the $1 / 330$ and $1 / 2000$ isopters determined by standard methods. It is, moreover, rather improbable that any such qualitative defect in the field would have resulted in so highly specific a disability.

\section{Summary}

A patient with mitral stenosis and auricular fibrillation developed, as a result of cerebral embolism, achromatopsia (colour agnosia) and an inability to identify faces and places. There was no loss of topographical memory and no difficulty in revisualizing faces.

Scotometric studies suggested small infarctions in each infracalcarine striate cortex.

The symptoms are analysed with special reference to their relation to $(a)$ agnosia and $(b)$ to the defects in the visual fields. The difficulties involved in attributing to them any precise localizing significance are mentioned.

The concept of prosopagnosia is discussed and its possible relation to a peculiar, and hitherto unrecorded, disorder of spatial thought is pointed out.

\section{REFERENCES}

Bay, E. (1953). Brain, 76, 515.

Bodamer, J. (1947). Arch. Psychiat. Nervenkr., 179, 6.

Charcot, J. M. (1883). Progr. méd., Paris, 11, 568.

Critchley, M. (1953). The Parietal Lobes. Arnold, London.

Goldstein, K. and Gelb, A. (1918). Z. ges. Neurol. Psychiat., 41, 1. Goldstein, K., and (1927). Mschr. Psychiat. Neurol., 66, 61.

Herrmann, G., and Pötzl, O. (1928). Die optische Allaesthesie. Karger, Herrmann, G.

Hoff, H., and Pötzl, O. (1937). Z. ges. Neurol. Psychiat., 159, 367. Holmes, G., and Horrax, G. (1919). Arch. Neurol. Psychiat., Chicago, 1,385 .

Jossmann, P. (1929), Mschr. Psychiat. Neurol., 72, 81.

Lissauer, H. (1889). Arch. Psychiat. Nervenkr., 21, 222.

Müller, F. (1892). Ibid., 24, 856.

Nielsen, J. M. (1941). A Textbook of Clinical Neurology. Hoeber, New York.

(1946). Agnosia, Apraxia, Aphasia. 2nd ed. Hoeber, New York.

Riddoch, G. (1917), Brain, 40, 15.

Spalding, J. M. K. (1952). Journal of Neurology, Neurosurgery and Psychiatry, 15, 99 and 169 .

Psychiatry, 15,99 and 169.
Teitelbaum, H. A. (1943). J. nerv. ment. Dis., , , $1,44$.

Teitelbaum, H. A. (1943). J. nerv. ment. Dis., '1, 44. Bergmann, Wiesbaden

Wolpert, I. (1930). Mschr. Psychiat. Neurol., 75, 207. 